\title{
A abertura política e a dignificação da função pública
}

\section{Política e nacionalidade na administração pública}

A reativação da vida político-partidária no Brasil nos últimos anos tem afetado o exercício da função pública em pelo menos duas formas essenciais. Prímeiro, através de um ataque generalizado aos chamados "tecnocratas", ou seja, aos funcionários públicos que tratam de fazer valer seus critérios prórios ou técnicos de decîsão sobre os mais variados temas, da política social à política econômica, sem submetê-los às injunções político-partidárias do momento. Segundo, pela utilização bastante ampla do emprego público como "moeda" política, ou seja, como um recurso utilizado não para o cumprimento de uma função pública qualquer, mas como um bem - um emprego - que se dá em troca de um apoio político específico, ou de um certo número de votos, Quando há troca de partidos no poder, um grande número de funcionários ligados à admînistração anterior é substituído por outras pessoas que tenham demonstrado sua lealdade ao vencedor. O predomínio de critérios políticos para a designação de servidores, tanto quanto para o condicionamento de suas ações, faz com que os mecanismos mais clássicos de admissão e promoção no serviço público - concursos públicos, mérito pessoal. qualificação técnica, etc. - tendam a ser postos de lado, substituídos por critérios de conveniência ou lealdade pessoal.

Seria um grave equivoco atribuir esta situação, simplesmente, a um amoralismo supostamente inerente à atividade político-partidária, que não hesitaria em renunciar aos valores de eficiência e probidade no serviço público em benefício de vantagens particulararistas e de curto prazo. Ainda que esta atitude certamente exista, ela se soma a um fenômeno mais profundo, que é a grande descrença que hoje existe em todo o país quanto ao poder real que têm os principios de racionalidade. mérito e competência técnica para produzir os benefícios econômicos e sociais que todos almejam. Em amplos setores da sociedade, na oposição como no governo, parece ter-se generalizado a idéia de que "os técnicos" já tiveram sua oportunidade e a desperdiçaram - por se isolarem nas torres de marfim de seus gabinetes refrigerados, e 
por cuidarem sobretudo de seus interesses pessoais e corporativos, antes que dos nacionais. Seria agora chegada a hora dos politicos, que conheceriam melhor a realidade do pais, de seu povo, e que por isto poderiam, quando necessário, dizer aos "técnicos" o que fazer.

Esta desqualificação da função pública pela politica está ligada, aparentemente, ao fato de que haveria, no Brasıl, uma curiosa correlação entre regimes fortes e esforços de racionalizar, reorganizar e valorizar o serviço público, por uma parte; e regimes abertos e o aviltamento da função pública por outra. Por exemplo, existe a idéla de que o Departamento Administrativo do Serviço Público o DASP, criado em 1938, fol a primeira tentativa realmente séria de dar ao serviço público brasileiro uma orgarizaç̃o racional baseada no mérito e competência, em um período de grande concentração de poder no governo federal. A abertura democrática de 1945 teria introduzido, pouco a pouco, elementos de clientela e empreguismo na administração pública federal, diminuindo a capacidade de ação do DASP e colocando em segundo plano todos os seus princípios de racionali-zação e eficiência. O processo de submissão do serviço público ao jogo político mais imediatista teria atingido seu auge na presidência de João Goulart, o que teria sido uma das causas mais importantes de sua queda'. O sistema administrativo brasileiro é reorganizado novamente em 1967, através do Decreto-Lei 200, que introduz novos principios a aumenta, mais uma vez, a eficiência do serviço público, até a crise que hoje, parece existir novamente.

Se esta interpretaçăo dos fatos fosse correta, ela nos confrontaría com um dilema. que colocaria de um lado a administração racional e técnica, associada aos regimes fortes e autoritários, e de outro a administração politizada, deficiente e desmoralizada, que pareceria ser um atributo da democracia e da participação social. No entanto, basta olhar- mos para os exemplos das democracias pluripartidárias européias para nos assegurarmos que isto não tem por que ser assim. Na realidade, não existe nenhuma incompatibilidade, em princípio, entre sistemas políticos abertos e intensamente disputados e serviços públicos competentes, respeitados e dignificados em suas funçōes. Mais ainda, os serviços públicos dos paises democráticos e pluripartidários são possivelmente os mais qualificados e competentes do mundo, quando vistos em comparação com as administrações públicas de outros regimes.

Podemos suspeitar, assim, que estamos diante de um falso dilema, baseado em premissas equivocadas. É possivel que, tratando de esclarecer estes equívocos, possamos pensar melhor em como manter e fortalecer a competência e dignidade do serviço público brasileiro, no regime político aber to e de ampla participação social que todos queremos construir.

\section{Primeiro equívoco: a \\ "administraçõo científica"}

O primeiro equívoco a esclarecer é o de que existiria algo que poderia ser denominado "administração científica", e que o siste. ma administrativo implantado no país através do DASP, em 1938، corresponderia a este modelo.

$\mathrm{Na}$ realidade, a idéia de que a administração pública é uma atividade eminentemente técnica, sujeita a leis científicas bem estabelecidas, fazia parte da justificação da criaç̃o do DASP durante o Estado Novo, e foi sempre utilizada pelos que criticaram e ainda criticam a intervenção da política na administração da coisa pública. Na sua versảo extrema, que até hoje encontra muitos adeptos, existiria um abismo profundo e insuperável entre o jogo das conveniências e dos interesses, que é o da politica, e a administração racional e técnica. A intromissão da política na administração, nesta perspecti- 
va, poderia ser até tolerada, em nome dos princípios mais altos da democracia, mas seria sempre um óbice para a boa execução da função pública.

Para os organizadores do DASP, a necessidade de uma administração pública racional e científica era uma decorrência natural do aumento da responsabilidade do poder executivo nos tempos modernos, particularmente para a direção da atividade econômica. "o direcionismo econômico tornou-se função primacial do Estado moderno", asseguravam. Não havia dúvida quanto à necessidade crescente da intervenção do poder público em todos os setores da atividade nacional. e para isto a racionalização administrativa era indispensável:

"Tal fenômeno (da necessidade de intervenção) traduzia o aumento constante da significação política do poder executivo, obrigado a agir cada vez com maior energia e presteza. Se, antes dessa expansão da esfera da atividade do Estado, a eficiência administrativa era a garantia do bom governo, agora. mais do que nunca, com o aumento da responsabilidade do Estado, ela se tornou o elemento indispensável da ação. Explica-se, destarte. porque o problema da organização do apareiho estatal, no mundo inteiro, passou a ser encarado em toda a sua plenitude, principalmente de 1930 para cá, isto é, quase imediatamente depois da grande depressão econômica mundial iniciada dramaticamente com o crack da bolsa de Nova lorque. Os governos tiveram que valer-se, também, do concurso indispensável da ciência e da técnica, para a montagem e funcionamento da máquina administrativa ${ }^{2 \prime \prime}$.

A realidade, no entanto, é que é no mínimo duvidosa a existência de uma ciência ou técnica específica que sirva de base para a "montagem e funcionamento da máquina administrativa". E claro que existe uma série de problemas e questões administrativas que requerem um certo conhecimento técnico. nas áreas de administração de pessoal , de material, sistemas de classificação de cargos e salários, etc. Mas a soma destes conhecimentos não chega a cornstituir o que muitos pretenderam que fosse uma "ciência administrativa", que permitiria criar no país uma "máquina administrativa", concebida em termos puramente tecnológicos, e alimentada por uma formação científica proporcionada aos administradores em escolas especializadas. 8asta examinarmos os currículos dos cursos brasileiros em administração pública para darmo-nos conta de que eles sempre foram. no máximo, uma junção pouco integrada de noções gerais de ciêncilas socilais, direito, economia, contabilidade e algumas técnicas administrativas. Sabemos que os princípios administrativos desenvolvidos por Taylor e Fayol, e que tanta voga tiveram em nosso meio, jamais chegaram a funcionar efetivamente nem mesmo no interior dos sistemas industriais, para os quais foram concebidos; e que devem ser entendidos, antes de tudo, como ideologias empresariais e administrativas para o controle da força de trabalho, e não como "principios cientíticos" em si mesmos $^{3}$.

$\mathrm{Na}$ prática, a "ciência da administração" difundida pelos defensores da administração cientifica no Brasil nunca passou de um conjunto mais ou menos bem organizado de noções de sentido comum. Sua principal função não foi a de dar um caráter científico à administração públíca, e sim de proporcionar ao governo central um mecanismo de controle sobre seu funcionalismo. Isto toi buscado através da centralização extrema da administração pública, sob a égide do DASP. e da criação de um quadro de pessoal integrado e coerente para todo o pais, sujeito a um sistema de classificação de cargos condizente com as diversas qualificações profissionais dos titulares, e regido por mecanismos explícitos de admissão e promoção. Havia certamente a idéia de que, por estes mecanismos, seria possivel dotar o país de um serviço público de elite. Mas sabemos que esta 
tentativa comeca a encontrar dificuldades ainda antes de 1945, já que o DASP jamais esteve, na realidade, imune às conveniências politicas do regime a que servia. Um autor que estudou o assunto, Lawrence S. Graham. observa que: "O programa de reforma admiristrativa parecia ser um importante sucesso. visto de fora; no entanto, quando examinamos os materiais deste período, fica claro que conflitos e oposições às reformas existiam dentro do próprio sistema administrativo. A estrutura administrativa do Estado Novo obscurecia esta situação. Os conf́litos entre os conceitos e práticas administrativas tradicionais e os modernos foram simplesmente internalizados"

O conflito que Lawrence observa é entre os estorços centralizadores do DASP e os procedimentos tradicionais de contratação e promoção de funcionários públicos por critérios de conveniência, por política de clientela. Mais importante do que isto, no entanto, era o fato de que a centralização e padronização que se buscava, se aumentava o poder do governo central sobre as administrações dos ministérios, na realidade retirava do serviço público sua eficiência técnica, o que era contornado pela criação de um semnúmero de organizações paraestatais ou autárquicas que, na prática, eram os órgãos pelos quais a política econômica se exercia. Caixas Econômicas, sociedades e institutos mistos (Departamento Nacional do Café, Instituto do Alcool e do Açúcar, Instituto Na. cional do Matel, empresas públicas de transportes (Estrada de Ferro Central do Brasil. Lóide Brasileiro, Administração dos Portos do Rio de Janeiro e do Pará) e os Institutos de Previdência Social são todas instituições anteriores a 1945, e que já caracterizavam a tendência da admînistração pública brasileira de criar mecanismos extraordinários e paralelos à administração direta sempre que resultados mais imediatos fossem realmente desejados 5 .

Em sua análise do período posterior a 1945, Lawrence Graham fala da existência, no Brasil, de duas ordens distintas dentro do serviço público brasileîro: uma legal, definida pelas normas centralizadoras e padronizadoras do DASP; e outra "funcional", ou seja, adaptada às necessidades da política de clientela dos partidos políticos dominantes. O resultado da interação destas duas ordens, diz ele, "foi um sistema administrativo que se tornou crescentemente formalístico, no qual a divergência entre as normas prescritas e o comportamento humano aumentava progressivamente ${ }^{6}$ ". A estas duas ordens haveria que acrescentar uma terceira, formada pelas autarquias, empresas estatais, grupos-tarefa, grupos executivos e outras formas não convencionais de organização do serviço público que eram as que os governos realmente utilizavam para a consecução de seus fins mais importantes.

Na medida em que este processo ia se acentuando, o funcionalismo público, submetido às normas administrativas gerais e centralizadas, ia sofrendo um processo gradual de desmoralização, com os salários corroidos prrogressivamente pela inflação, e com os funcionários admitidos pelo sistema de clientela destruindo, pela sua simples presenca, o que restava de um sistema de mérito que havia sido tentado no passado. O sistema administrativo centralizado tinha ainda uma grande desvantagem, que era a de inibir quase totalmente a ação da administração pública em tudo o que fosse além das atividades meramente rotineiras. Em contraste, as unidades descentralizadas łinham autonomia financeira, podiam fixar salários por valores competitivos com o mercado privado, e ter a sensação de que desempenhavam uma funçăo socialmente útil.

E claro que este processo foi se dando de forma desigual, e com muitas idas e vindas. Autarquias formadas, a principio, de forma descentralizada e com bastante autonomia, terminaram revertendo aos controles rígidos e formalistas da administração direta. Outros setores do governo foram capazes de 
manter sua qualidade e competência, ao lado de um forte sentimento de lealdade dos funcionários às suas instituições. E notória, por exemplo, a competência do Ministério das Relações Exteriores em preservar os mecanismos de seleção e promoção de seu pessoal, a partir de uma escola própria que proporciona a seus funcionários uma base de conhecimentos e valores comuns. O Instituto de Aposentadoria e Pensão dos Industriários é também um exemplo, talvez menos conhecido. de um setor da administração que foi preservado do clientelismo que imperou na maior parte do sistema previdenciário, e deu origem a uma elite administrativa que teve grande impacto em todo o desenvolvimento do sistema previdenciário do pais ${ }^{7}$. As forças armadas brasileiras, desde os anos 30 evoluiram progressivamente no sentido da criação de um forte espírito corporativo e da afirmação do princípio de profissionalização do militar ${ }^{8}$. O Banco do Brasil e o Banco Nacional de Desenvolvimento Econômico são outros exemplos bastante citados.

Mas o fato de não existir, na realidade. uma "Ciência da Administração" com maiúsculas, não é suficiente para explicar as razōes das dificuldades do serviço público brasileiro. Se a "administração científica" não funciona como um corpo formado de conhecimentos, ela pode, no entanto, funcionar como uma ideologia de legitimação de uma administração pública que extrai sua competência de outras fontes. Assim parece ter ocorrido, por exemplo, nos Estados Unidos, de onde as teorias da "administração cienti" fica" nos vieram. Para esclarecer melhor a questão, é inevitável que discutamos um pouco as idéias de um autor que é por muitos considerado como um dos principais teóricos da administração racional no passado: Max Weber.

\section{Segundo equívoco: a racionalidade burocrática (ou a má-leitura de Max Weber).}

Autor de imensa obra, especialmente no campo da história social da religião, da economia e do direito, Max Weber é conhecido entre nós principaimente como o proponente de um modelo de burocracia racional. Weber tem um texto famoso, em que dá uma lista bastante grande das características desta burocracia: separação entre pessoa e cargo. regras escritas para todos os atos públicos, neutralidade dos funcionários em relaçāo ao conteúdo de seus atos, profissionalização, etc. ${ }^{\circ}$. A palavra "burocracia", neste contexto, não tem o sentido negativẹ que ela veio a adquirir mais tarde. Ao contrário، a burocracia para Weber representaria a forma mais eficiente e racional de exercicio do governo, se vista em comparação com outras formas de administração (como, por exemplo, a de tipo patrimoniall.

A má leitura de Weber consiste em considerar que seu "modelo" de burocracia é uma receita para a organização da máquina burocrática; uma receita que, bem aplicada, geraria a administração científica e técnica que tantos buscam ${ }^{10}$. Na realidade, o que Weber faz é dar as características "ideais" de uma administração pública que existiria em um contexto social e político bem determinado; ela não é, de nenhuma maneira, a forma mais eficiente e racional de organização social para a realização de terminados fins; $e$. mais importante, ela não pode existir no vazio, mas requer uma série de condições externas bastante especificas. Examinemos em primeiro lugar estas condições externas, para depois voltarmos à questão da eficiência

A burocracia moderna, para Weber, é a forma de organização do Estado própria dos regimes que ele denomina de "dominação racional-legal", por contraste a outras formas de dominação política (carismática e patrimonial). A dominação carismática se carateriza por uma liderança pessoal extremamente forte, e uma máquina administrativa dotada de intensa lealdade e dedicação de seus membros. Neste sentido, é uma forma organizativa das mais eficientes. No entanto, ela tem 
dificuldades em se organizar e se manter ao longo do tempo, e de incorporar os procedimentos técnicos normais das grandes organizações. $\mathrm{Na}$ dominação caristmática, o que importa são sempre os fins, e nunca os meios ou as formas de chegar até eles; a não ser quando as próprias formas e procedimentos adquirem, elas mesmas, características ritualizadas e sagradas.

A dominação patrimonial lque é uma variante da chamada "dominaçăo tradícional") jå permite a criação de grandes estruturas administrativas, procedimentos bastante complexos de controle e prestação de contas, etc. Suas principais características são. por um lado, a não separação entre o que é público e o que é privado; e, segundo, o exercício de funções públicas por particulares. São coisas parecidas, mas não idênticas. No primeiro caso, as pessoas governam, cobram impostos, desempenham funções jurídicas, etc. em interesse próprio: o caletor de impostos é sócio do governo, o prefeito explora as terras de municipalidade e fica com parte dos lucros, os funcionários são "donos" dos cargos que exercem, e estes cargos podem ser comprados, cedidos pelo governo como parte de prêmios e honrarias, e mesmo transmitidos hereditariamente. No segundo caso, são os nobres que armam seus camponeses para as guerras, e que passam períodos regulares na corte a serviço dos reis.

A dominação racional-legal, ou burocrá tica, não é, para Weber, uma forma de ad ministração governamental "mais desenvolvida" ou "mais moderna" que as outras, mas algo completamente distinto, baseado em premissas também diferentes.

A mais importante destas premissas, de tipo político, é a subordinação do sistema governamental e administrativo a um sistema de poder externo a ele. De fato, o princípio fundamental da burocracia racional weberiana, enquanto "típo ideal", é que ele deva responder da maneira mais eficiente possivel ao governo, que por sua vez responde a um parlamento ou a um sistema político partidário. Quando este princípio está em vigor, então fica claro que os administradores não podem ter "interesses próprios" em suas ações.

Eles devem agir em tunção de mandatos políticos específicos, que tendem, em geral. a adquirir forma de leis e regras escritas. São os corpos da ação dos administradores. Hoje sabemos, pela experiência universal, que este aspecto legalista da burocracia de tipo weberiano pode significar, muitas vezes, perda de eficiência, formalismo, e a reversão para aqueles aspectos que deram má fama ao termo "burocracia". No entanto, ele é inseparável do conceito original, como característica central de uma administração realmente a serviço de uma ordem política que define seus objetivos autonomamente.

Uma vez lançada esta premissa inicial. coloca-se a seguinte pergunta: como conseguir que existam pessoas que se dediquem a esta atividade administrativa e burocrática de forma intensa, honesta, competente e profissional? Na dominação tradicional o burocrata se locupletava; na dominação carismática, ele depositava sua fé no líder. E ago$\mathrm{ra}$ ?

A resposta é que a moderna burocracia consegue lealdade e dedicação da mesma forma que as diversas profissões modernas o fazem: Através do desenvolvimento de uma ética profissional específica, vinculada a um sistema satisfatório de gratificações materiais, e conduzindo a um reconhecimento social significativo. Nesta perspectiva o administrador seria um profissional equivalente ao médico, ou ao advogado: ele passaria por escolas próprias, seria membro de uma coletividade relativamente restrita onde todos compartem a mesma cultura, teria um código de ética e valores desenvolvido no seio desta coletividade e seu sucesso profissional - sua promoção, suas responsabilidades, seu prestígio - dependeriam de sua adesão a es- 
te códıgo, combinado com um segundo elemento chave: a competência. Pois, da mesma maneira que os outros profissionais, os administradores deveriam ser capazes de dominar um conjunto bastante amplo de conhecimentos úteis a tarefa administrativa, que tenderiam finalmente a se organizar como uma "ciência administrativa" própria.

Este breve resumo das noções weberianas já permite entender uma questão fundamental: não é a existência de uma ciência administrativa que permite o surgimento de um serviço público digno e competente; ao contrário, é a existência de condições políticas e socioculturais necessárias à dignificaçăo do serviço público que pode, inclusive, conduzir a tentativas de organização de algo que poderia aproximar-se a uma "ciência administrativa". Entender este ponto é fundamental para ver, com toda a clareza, como a simples introdução de princípios de racionalidade no serviço público brasileiro, tentada anos atrás através do DASP, jamais poderia levar aos resultados que se esperavam.

\section{Algumas dificuldades da racionalidade burocrática}

$\mathrm{Na}$ sua forma ideal, a burocracia weberiana nunca chegou a existir. Na realidade, ela parece ser um modelo dotado de grande instabilidade, com várias dificuldades que the são inerentes. A primeira foí prevista pelo próprio Weber, ou seja, a tendência das burocracias em desenvolverem seus interesses próprios como corporação, e assim deixarem de ser porta-vozes e agentes tão eficazes dos governos. É claro que o desenvolvimento de uma ética corporativa própria é fundamental para qualquer grupo social que pretenda manter altos seus padrões de qualidade, desempenho e ética de trabalho. Ao mesmo tempo, no entanto, isto pode levar a um excesso de poder por parte deste grupo, pela criação de um sem número de regras e procedimentos administrativos que na realidade só interessam a ele próprio. O exemplo maîs tí- pico disto são as normas de sigilo que envolvem um grande número de atos administrativos, e cuja principal função é proteger os administradores de uma avaliaçāo majs eficaz por parte dos partidos políticos e da opinião pública. A segunda é a apatia, que transforma a ação formal e legal do administrador em comportamento ritualista e desinteressado, e por isto ineficiente.

Esta dificuldade é acrescida de uma terceira, talvez ainda mais séria. A complexidade crescente dos Estados modernos, e o aumento das funções que este Estado desempenha, faz com que seja impossível continuar mantendo a estrita separação que Weber supunha entre a elaboração das leis e sua execução. Este princípio ainda hoje está presente na totalidade, ou quase, dos regimes políticos democráticos. No entanto, é bastante claro que agências governamentais responsáveis por uma série de atos, da política social à política ambiental e econômica, têm que tomar decisões pormenorizadas quase diárias, que trazem um conteúdo político bastante óbvio, na medida em que beneficiam determinados interesses em detrimento de outros. Enquanto isto, os órgãos políticos - os partidos políticos, os legislativos, etc. dificilmente desenvolvem a competência técnica específica para tomar as decisões políticas que muitas vezes são deles esperados. Pela própria complexidade crescente do processo político, eles tendem a se especializar nas questões mais diretamente político-partidárias, ou seja, aquelas que têm repercussões mais diretas e visíveis sobre a distribuição do poder na sociedade. Em outras palavras, a distinção entre o que é técnico, formal ou administrativo de um lado, e o que é político e substantivo, por outro, é hoje bastante obscura, e não há indicações de que tenderá a se clarificar no futuro. Isto faz com que a burocracia acrescente à sua tendência natural de defender seus interesses corporativos uma segunda característica: a tendência a querer subtrair dos órgãos políticos a própria competência decisória, em nome de sua major capacitação técnica. 


\section{A buscade modelos alternativos}

Já vimos que a resposta brasileira às dificuldades de organização do serviço público tem sido, tradicionalmente, a criação de agências governamentais insuladas e protegidas das regras e dos vícios do serviço público mais geral, sejam os do formalismo daspiano, sejam os do clientelismo. Um total de 250 agências deste tipo foram criadas entre 1930 e 1977 pelo governo federal, sendo 56 no período 1930-63 (com maiores concentraçães nos períodos do Estado Novo e de Jaão Goulartl e 194 no período 1964 a 1977 (com maiores concentrações no governo Geisel)"'.

A desconfiança que esta tendência revela de nossos governantes em relação ao sistema administrativo centralizado é, assim. endêmica e independe de regimes e ideologias políticas. No entanto, ela em geral não se explicita, não surge como uma proposta de organização admínistrativa de tipo alternativo, e por isto debilita ainda mais o serviço público tradicional, sem criar normas adequadas para a administração e o controle deste sistema descentralizado e crescente.

Existe, no entanto, um momento importante na história administrativa do Brasil em que esta crítica é formulada com todas as letras e assume forma de lei, ou seja, o Decreto-Lei 200, de 25.02.1977, na gestão de Hélio Beltrão no Ministério do Planejamento. Existe uma palestra de 1965 do Ministro Hélio Beltrão, publicada sob o título de "A Reforma Administrativa Federal", que sintetiza bastante bem a crítica ao sistema anterior e as novas concepções que seriam incorporadas na legislação.

Para Beiträo, as dificuldades do serviço público brasileiro provinham, basicamente, da tendência à centralização e da idéia de que caberia à União a execução direta de todos os atos administrativos importantes. A concentração dos poderes nas mãos da União no lugar dos estados e municípios, a tendência às leis e regulamentaçôes minuciosas, a deterioração progressiva do sistema de mérito eram vistos como outros fatores negativos a exigir solução. A reforma proposta era, basicamente, no sentido de delegar ao máximo o poder de decisão para os órgãos de linha, e preferir sempre a contratação de setores e companhias privadas para a execução de suas políticas. Segundo este modelo. os órgãos administrativos deveriam se limitar a funções quase que exclusivamente normativas e de supervisão, enquanto que o setor privado passaria a ter um papel cada vez maior em todas as açōes realmente executivas do governo. As duas premissas implícitas no projeto são, primeiro, a de que o Estado é sempre um executor incompetente, e que o setor privado pode fazer o mesmo que ele de forma mais efícaz e barata; $e$, segundo, que é impossivel legislar em detalhe a atuação dos órgãos de linha da administração pública. São premissas que têm implicações importantes, e merecem discussão aprofundada.

\section{A privatização do serviço público}

Por que o setor privado seria mais eficiente do que o serviço público? A resposta tradicional é que o setor privado está sujeito às pressões do mer cado competitivo, enquanto que o serviço público não sofre este tipo de restriçōes. Albert Hirschman, em trabalho que se tornou clássico, mostra como existe um mecanismo alternativo ao de mercado para aumentar a eficiência das instituições, que é a voz e o protesto do público diretamente interessado em seu desempenho; e mostra também como situações de monopálio podem produzir no setor privado os mesmos problemas que parecem ser crônicos e típi$\cos$ da administração governamental ${ }^{12}$. A crença na superioridade da administração privada foi, certamente, um dos fatores que inspiraram o Decreto-Lei 200; o outro foi o conhecimento das dificuldades quase insuperáveis de agir com efíciência dentro do emaranhado de normas e formalismos que hoje existem no serviço público brasileiro. Neste sentido, há algo de comum entre a orienta- 
ção privatizante deste decreto e a proliferação de empresas e fundações estatais que ocorreram no Brasil nos anos seguintes.

Não que o Decreto-Lei 200 tivesse como intenção o crescimento do setor estatal, muito pelo contrário. Mas, como o setor privado freqüentemente não tinha a organização e a competência para a execução das tarefas mais técnicas que o governo pretendia lhe atríbuir, as únicas alternativas eram o recurso a empresas privadas estrangeiras ou a criação de empresas nos moldes privados mas com capital e controle públicos, e que pudessem agir sob a orientação de um órgão normativo superior. Esta combinação de órgãos nor mativos superiores, da administração direta, e órgãos executivos subordinados, organizados como fundações ou empresas estatais, passou a ser adotada em muitos setores da administração pública. Uma conseqüência inesperada foi que, na maioria das vezes, as empresas executoras passaram a concentrar a maior parte da competência técnica e dos recursos financeiros, esvaziando assim, na prática, as funções de seus órgãos normativos, ou entrando em conflito com eles.

Um outro fenômeno que ocorreu foi o surgimento de um grande número de empresas privadas que foram organizadas com a função quase que exclusiva de atender aos contratos do setor público. Estas empresas tinham, em relação ao serviço público, a vantagem da simplicidade operacional e da informalidade; por outro lado, não participavarn, realmente, de um mercado competitivo. O exemplo mais importante talvez seja. aqui, o das grandes empreiteiras privadas, criadas para a realizaçăo de grandes obras de engenharia. Com o tempo, elas se transformaram em clientes dificilmente saciáveis de contratos públicos، exigindo que novas obras fossem constantemente contratadas não tanto pelos seus resultados, mas para manter ativo e empregado seu pessoal e seu equipamento.

É assim que a simplificação burocrática e a preferência pelo executor privado acabou por gerar, como que pela porta dos fundos, um novo tipo de clientelismo, talvez mais caro e potencialmente mais danoso que o anterior, que é o clientelismo dos interesses particulares desenvolvidos à sombra do serviço público. Este problema está ligado a um outro princípio básico da reforma de 1967, que que o da descentralização das decisões.

A questão é bastante complexa, na realidade. Por uma parte, toda a experiência brasileira e internacional mostra que nenhum governo é capaz de manter centralizadas as decisões, principalmente na área de política social e econômica, sem cair no formalismo, na rigidez e na ineficiência. Por outra, a delegação da autoridade decisória para os níveis inferiores da burocracia pode significar, na prática, uma renúncia à capacidade de ação política dos governos. Idealmente - no modelo weberiano - só haveria delegação da execução, nunca das decisões enquanto tais, que seriam privativas dos órgãos políticos do governo. Na prática, muitas vezes os órgãos, políticos não têm a capacidade operacional e técnica de tomar as decisões, e por isto as delegam para os órgãos executivos. No Brasil, isto significa, de fato, passar muitas decisões aos órgãos normativos, e destes aos órgãos executivos, organizados freqüentemente como empresas públicas, e até mesmo como empresas privadas. Uma discussão bastante crítica desta política de descentralização das decisões nos Estados Unidos, que teve grande repercussão anos atrás, levou à proposta de uma nova centralização da administração pública daquele pais ${ }^{13}$. No Brasil, vários críticos já têm chamado a atenção para a coalização de interesses que se estabelece entre or gãos descentralizados da burocracia e grupos privados, que terminam por serem totalmente impermeáveis a tentativas de mudança de política vindas de cima ${ }^{14}$.

Um último aspecto da privatização do serviço público a ser mencionado é o insulamento das empresas estatais em relação ao mercado. Como vimos anteriormente, a ten- 
dência histórica no Brasil tem sido a de insular certos setores da administração dos problemas do formalismo e clientelísmo próprios da administração direta, e uma das formas disto tem sido a criação de empresas estatais que teriam a vantagem de participar competitivamente do setor privado. Os niveis de salário destas empresas, por exemplo. deveriam ser competitivos com os do mercado, e isto explicaria os altos salários de seus executivos, e os bons níveis de remuneração dos técnícos. Estas empresas tambem deveriam visar o lucro, que seria um dos principais parâmetros de seu desempenho.

Se a expansão da economia no início dos anos 70 permitiu o florescimento deste tipo de empresas, os anos 80 mostram que elas tenderam a se insular cada vez mais do setor privado, e a buscar um status especial dentro do setor público. As vantagens que elas ofereciam a seus funcionários nos anos de expansão - bons salários, estabilidade. benefícios secundários de vários tipos - passaram a se constituir em privilégios em uma economia em estagnação ou recesso. A lucratividade empresarial raramente é utilizada como critério efetivo de avalíação, já que existem sempre razões políticas e sociais que ditam as decisões de investimento, custos, etc. E, finalmente, concessões especiais de crédito, monopólios e îsenções fiscais fazem dos custos e da lucratividade destas empresas algo bastante fictício de um ponto de vista de mercado. Agora, estas empresas que haviam sido criadas fora do serviço público centralizado para proporcionar ao Estado maior agilidade, eficiência e economia pasaram a ser apontadas como as principais responsáveis pelos grandes gastos, pela ineficiência e pelos privilégios indevídos da burocracia governamental.

\section{Em busca de uma soluçāo}

$\mathrm{Na}$ perspectiva de hoje, pareceria que todas as soluçōes foram tentadas, e que nenhuma realmente funcionou, no sentido da criação de uma administração pública mais eficiente, competente e dignificada. $\mathrm{Na}$ realidade, existe hoje um obstáculo óbvio para qualquer tentativa que se faça para a melhoria do serviço público brasileiro, que é ser ele um grande empregador e contratador de serviços, que não pode ser reduzido sem levar a problemas sociais de curto prazo bastante graves. Mais do que um expediente político, o empreguismo no setor público é hoje, no Brasil, um fator de atenuaçăo do impacto mais imediato da crise econômica sobre um grupo de interesse relativamente bem articulado e politicamente ativo, que são os funcionários e os empregados das empresas estatais.

Isto, entretanto, não bastaria. Não é suficiente eliminar do serviço público os mais incompetentes ou seus setores mais ineficientes e caros. É bastante provável - faltam dados a este respeito, que seria importante conseguir - que uma boa parte destas pessoas sejam ou tenham se tornado obsoletas do ponto de vista profissional, pelo tempo passado sem um trabalho tecnicamente competente, pelo isolamento, pela própria idade. Qualquer programa de diminuiçāo do peso da máquina administrativa governamental deveria ser combinado com um trabalho intenso de avaliaçäo e reciclagem das pessoas com potencialidade para se transferirem para o setor privado, e com mecanismos adequados de apoio aos que já não podem fazer esta passagem.

Mas o ideal conservador norte-americano, de uma administração pública a mais econômica e reduzida possível, que pudesse dar apoio a um setor privado cada vez mais pujante e independente, parece afastar-se cada vez mais da realidade nos próprios Estados Unidos, e não ter muito a ver com sociedades como a nossa, que têrm uma longa tradição de participação do Estado em amplos setores da vida social. Basta pensarmos em dois setores de grande impotância, a educação e a previdência social, para darmo-nos conta disto. 
Os paises europeus viveram durante muitos anos o dilema da educação pública vs. educação privada. A educação pública aparecia na visão de seus proponentes como educação igualitária، universal, agnóstica e democrática: a educação privada era, sobretudo, reivindicada pela Igreja, e baseada na ídéia de que as famílias deveriam ter o direito de dar a seus filhos a educação que mais Ihes conviesse, livres da tutela do Esta do. A maioria dos paises desenvolveu um sistema educacional duplo, ou seja, com um amplo setor público e um setor privado mais restrito, proporcionando uma educação de elite. Com o tempo, no entanto, as escolas privadas de elite passaram a depender cada vez mais de apoio público, e hoje é muito dificil, se olharmos por exemplo o cenário educacional norte-americano, nos lembrarmos de que as universidades de Harvard. Stanford e Yale são privadas, enquanto que a de Berkeley é pública. No Brasil a questão do ensino privado tem sido não a da liberdade do ensino privado e religioso, mas a da subvenção pública ao ensino realizado privadamente. A discussão tem muitos pontos de semelhança com a da açâo administrativa direta ou indireta, que examinamos anteriormente: os defensores do ensino privado argumentam que o Estado é mau professor, que custos educacionais públicos são excessivamente altos, que seria mais econômico, eficiente e democrático distribuir os recursos educacionais para as escolas privadas, tanto ao nivel secundário quanto ao superior.

Os argumentos contrários são bastante conhecidos. É claro, por exemplo, que o ensino superior público é, geralmente, de muito melhor qualidade do que o privado, no caso brasileiro. Não existem mecanismos que garantam que a atividade empresarial na área do ensino não se transforme em simples indústria, desinteressada do conteúdeo e da qualidade do aprendizado. Os professores do ensino privado são explorados, trabalham muito, ganham pouco, não têm direitos de associação e participação na vida de suas instituições.

O que esta discussão revela é que não se está debatendo, na realidade, se o Estado deve ou não participar da educação, e sim a forma desta participação. Ela revela também que, se a execução direta da taref́a educativa pelo Estado traz problemas, sua transferência de forma subsidiada ao setor privado não é nenhuma garantia de melhor desempenho.

O caso dos serviços de saúde tem um certo paralelismo com o da educação. A organização profissional dos médicos na forma de uma profissão liberal, com liberdade de escolha por parte dos pacientes e liberdade de preços por parte dos médicos, proporcionou durante bastante tempo um atendimento médico privado de qualidade bastante razoável, para o público com condições de pagá-lo. O aumento dos custos da medicina e a ampliaçảo do atendimento médico a amplas camadas da população com pouco poder aquisitivo levaram em um primeiro momento à criação de um sistema de atendimento médico como parte integrante do serviço público, que pouco depois passou a se exercer na forma de contratos com o setor privado. Ainda aqui, os argumentos são semelhantes aos de outros setores. A medicina pública seria desnecessariamente cara, burocratizada. e além de tudo totalitária, por eliminar a liberdade de escolha do paciente. A contratação dos serviços privados garantíria a manutenção da medicina como profissão liberal, mantería os custos reduzidos e asseguraria a liberdade dos pacientes.

$\mathrm{Na}$ prática, sabemos que as coisas não funcionaram desta maneira. O subsídio indiscriminado à medicina privada permitiu uma escalada aparentemente incontrolável dos custos médicos, sem muita possibilidade de se distinguir onde terminam as exigências técnicas da boa prática profissional e onde começam os abusos e a corrupção pura e 
simples. A medicina, tanto quanto a educação, não pode reverter à condição de atividade privada, a não ser em um pequeno número de casos, e para uma minoria da população. E a simples subvenção pública à ativídade privada tira dela um de seus principais elementos de controle de qualidade, que é o cálculo de custos do usuário, que por sua vez pressiona o provedor dos serviços para proporcionar aquilo que os clientes - ou alunos - realmente querem.

Os exemplos da educação e da medicina também servem para lembrar que o serviço público requer hoje uma gama extremamente variada de competências, e que não é possivel mais pensar em formar um tipo universal de "administrador públi-

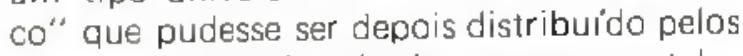
diversos setores da máquina governamental.

Se isto é verdade, pareceria que a única maneira de aumentar a competência e a dignificação do serviço público seria através de um esforço sistemático de dotar os diver. sos setores especializados da administração pública de uma formação adequada, um sentido de missão e responsabilidade pública $\mathbf{e}$ de formas adequadas de remuneração que sejam específicas para cada caso, e compatíveis com ambiente social mais geral. É claro que ísto é fácil de dizer, mas difícil de executar. No entanto, não é impossivel, desde que algumas condições mais gerais sejam buscadas:

a) Há que haver uma decisão política sobre cada uma das áreas da administração pública a ser desenvolvida. Não basta uma decisão genérica, como tantos projetos e leis de reformas administrativas do passado.

b) Uma vez tomada a decisão sobre a área a ser desenvolvida, ela deve ser submetida a um processo de avaliação aprofundado. que não pode, naturalmente ser entregue aos próprios interessados pelas formas administrativas existentes. c) Ao atacar-se uma área por vez é possivel fazer remanejamentos, transformações organizacionais, transferências de pessoal. etc., que seriam impossiveis de realizar em programas de reforma administrativa global.

d) Especial atenção deve ser dada aos centros de formação e treinamento dos funcionários de cada área. Existe uma tendência de os diversos setores da administração desenvolverem suas próprias escolas superiores, nos moldes da Escola Rio Branco, do I tamarati. O perigo, no entanto é que estas escolas ministeriaîs se isolem do mundo universitário e acadêmico, e terminem por proporcionar um conhecimento de segunda classe. Parece mais adequado fazer com que os diversos setores especializados da administração pública desenvolvam relações intensas com instituições universitárias de graduação e pós-graduação, proporcionando elas mesmas, eventualmente, cursos maîs específicos.

e) Finalmente, é necessário dar ao funcionário público um sistema de salários adequado. Isto significa, obviamente, que seu nível de salários, possibilidades de promoção e desenvolvimento pessoal não sejam significativamente inferiores ao do setor privado. Ao mesmo tempo, no entanto, eles não podem ser tão altos que coloquem o funcionário em uma situação de intangibilidade e irremovibilidade. Um dos fenômenos perversos, e pouco notados, de insulamento recente das empresas públicas foi o da esterilização precoce de jovens técnicos contratados em inicio de carreira por salários muito acima dos valores do mercado, e que depois $\mathrm{fi}$ caram sem condições, quer de promoção e melhoria em sua empresa, quer de recomeçar suas carreiras a partir de patamares mais baixos.

Em resumo, o serviço público, para ser realmente dignificado, tem que deixar de ser um simples emprego, uma simples sinecura. ou a venda de um serviço, para recuperar seu sentido de missão. Isto pode ser feito, desde 
que haja uma vontade política para tal, e desde que nos livremos dos velhos conceitos e preconceitos da "administração científica" por um lado, e da maldade inerente a setor público, por outro.

A questão da "decisão política" é crucial, e nos traz de volta ao tema da relação entre a abertura política e a dignificação da funç̃̃o pública.

Antes de mais nada, uma "decisão política" não pode significar hoje, simplesmente. um ato de governo, mas uma decisão tomada com a participação de amplos setores da sociedade, através de seus órgãos representatiVos, sindicatos, associações profissionais, etc. E necessário que o esforço de valorização do serviço público não seja visto e apresentado como um simples ato técnico, mas como algo que realmente busque atender os interesses de toda a coletividade, e do qual ela participe e esteja informada. Segundo, a participação social em um "ato político" desta natureza não pode se dar somente ao nivel das organizações políticas formais - os órgãos legislativos, os governos estaduais e municipais, etc. - mas também através de grupos e instituições sociais que tenham interesse direto no setor administrativo a ser mobilizado. O modelo democrático clássico, pelo qual o controle político do governo se fazia somente pelo sistema eleitoral e pelo legislativo, já não se sustenta. Ainda que as decisões mais gerais e cruciais devam ser tomadas neste nivel mais alto, é impossivel discutir e agir na área do planejamento urbano, por exemplo, sem tomar em conta as opiniões $e$ os interesses das associações de moradores e dos profissionais de arquitetura e urbanismo que tenham condições de contribuir. A administração pública hoje em dia tem que estar sujeita ao controle social e político pelos dois extremos, e é este controle que the dá, também, legitimidade para resistir aos embates inevitáveis do clientelismo eleitoreiro

A abertura política pode, em resumo, trazer em seu bojo os mecanismos mais fundamentais para a real dignificação do serviço público no país, livrando-o da pecha de "tecnocrata", evidenciando "' ' importância para todos os setores da sociedade, e fazendo com que ele consiga se preservar do uso meramente particularista e privado. Não existe, certamente, fórmula mágica para dar ao Brasil, amanhã, o serviço público de qualidade que o pais nunca chegou a ter. Mas existem caminhos razoavelmente claros de melhoria, a serem seguidos.

\section{Notas}

1. A intensificação do uso da administração pública como moeda política é bem evidenciada por Wanderley Guilherme dos Santos em The Calculus of Conflict (ver referências completas na bibliografia).

2. Extraido de "A modernizaçāo do Estado", em Estado Novo, um auto-retrato, p 48-9.

3. O aspecto predominantemente ideológico das idéias de Taylor é analisado com profundidade no trabalho de R. Bendix, Work and Authority in Industry. Randall Collins faz uma análise semelhante quanto ao conteúdo dos cursos de administração de empresas nos Estados Unidos. A importância dada a Taylor e Fayol pelos teóricos da "administração pública científica" no Brasil é bem documentado por Lawrence Graham.

4. Civil Service Reform in Brazil, p. 186 (a tradução é nossa). O trabalho mais abrangente sobre o tema é, possivelmente, o de Beatriz M. de Souza Wahrlich, publicado quando este texto já estava pronto.

5. Não deixa de ser curioso observar que, apesar de o DASP justificar sua criação pela necessidade de planejamento e racionalização da ação econômica do Estado, é exatamente na esfera da ação econỏmica que é 
criada a maioria das agências administrativas paralelas.

6. Graham, p. 158.

7. Sobre a importância histórica do |API, veja o estudo de James M. Malloy sobre o sistema previdenciário brasileiro, entre outros.

8. As principais análíses deste processo são as de Alexandre Barros, Edmundo Campos Coelho e José Murilo de Carvalho.

9. O texto sobre burocracia faz parte de uma antologia de Weber publicada nos Estados Unidos em 1946 e que teve ampla difusão, sendo inclusive traduzida no Brasil. Trata-se da antologia editada por Hans Gerth e C.W. Mills.

10. E um erro no qual não incorreu Alberto Guerreiro Ramos, que em 1946 publicou um excelente sumário da sociologia weberiana، a partir da publicação da tradução espanhola de Economia e Sociedade. Para Guerreiro Ramos, longe de ser um receituário, a sociologia weberiana deveria se constituir em instrumento para fazer com que "a técnica da administração adquira a consciência de suas relações estruturais com os demais departamentos do todo político-social e, desse modo, possa intervir no processo social, não com expedientes perturbadores, mas colaboradores e até estimuladores daquelas forças de cuja libertação depende a realização mesma das potencialidades representativas de uma época" (A Sociologia de Max Weber, p. 139).

11. Dados apresentados por Edson Nunes e Bárbara Geddes, a partir de informações originalmente organizadas por Wanderley GuiIherme dos Santos.

12. O texto de Hirschman tem também tradução brasileira.

13. Trata-se do livro de Theodor Lowi, The End of Liberalism.
14. Fernando Henrique Cardoso cunhou a expressão "anéis burocráticos" para caracterizar este tipo de coalizões.

\section{Referências bibliogróficas}

BAAFOS, Alexandre de Souza Costa. The Military Professional Socialization - political performance and state building. (tese de doutoramento). Chicago, Universidade de Chicago, 1978، (manuscrito).

BELTRAo, Hélio. A Reforma Administrativa Federal. Brasília, s/d.

BENDIX. Reinhardt. Work and Authority in Industry. New York, John Willey \& Sons, 1968.

CARDOSO, Fernando Henrique Autoritarismo e Democratizacão. Rio. Editora Paz e Terra, 1975.

CARVALHO, José Murilo. Armed Forces and Politics in Brazil, 1930-1945. Hispanic American Historical Review, vol. 62. 2 , 1982, pp.193-223.

COELHO, Edmundo Campos. Em busca da identidade: o exército e a política na sociedade brasileira. Rio de Janeiro, Forense Universitária, 1968.

COLLINS, Randall. The credential society. New York, Academic Press. 1979.

GRAHAM, Lowrence S. Civil service reform in Brazil: principle vs. practice. Austin: University of Texas Press، 1968.

HIRSCHMANN, Albert O. Exit, Voice and Lova/ty. Boston: Harvard University Press. 1980.

LAFER, Celso. O Sistema Político Brasileiro. São Paulo: Editora Perspectiva, 1975. .

LOWI. Theodore J. The end of liberalism. New York, W.W. Norton \& Co., 1969. 
MALOOY, James M. The politics of social security in Brazil. Pittsburgh, University of Pittsburgh Press, 1979.

NUNES, Edson e Geddes, Barbara, Clientelism and Political Insulation: towards a political sociology of contemporary Brazil. Trabalho apresentado d̀ "Conferência sobre Oportunidades e Problemas em Sociedades Industriais Periféricas: o casa do Brasil"." Nova Friburgo, julho de 1983 (texto preliminar).

RAMOS, Alberto Guerreiro. A Sociologia de Max Weber: sua importância para a teoria e a prática da administração, Revista do Serviço Público, vol. 3, nọ 2/3 lagosto/setembrol, 1946.
SANTOS, Wanderley Guilherme. The Calculus of Conflict. (tese de doutoramentol. Universidade de Stanford, Departamento de Ciência Política, 1979 (manuscrito).

SCHWARTZMAN, Simon (organizador). Estado Novo, um Auto-retrato. Brasília, ed. Universidade de Brasília, 1983

WAHALICH, Beatriz M. de Souza, Reforma Administrativa na Era de Vargas. Rio de Janeiro, Fundação Getúlio Vargas، 1983

WEBER, Max. Essays in Sociology. (Textos traduzidos, editados com introdução de H.H. Gerth e C.W. Milis) . Oxford University Press, 1946. 